\title{
MODELLING AND SIMULATION OF A NOVEL MODULAR FIXTURE FOR A FLEXIBLE MANUFACTURING SYSTEM
}

\author{
Matejic, M. ${ }^{*}$; Tadic, B. ${ }^{*}$; Lazarevic, M. ${ }^{* *}$; Misic, M. ${ }^{* * *} \&$ Vukelic, D. ${ }^{* *}$ \\ * University of Kragujevac, Faculty of Engineering, Sestre Janjic 6, Kragujevac, Serbia \\ ** University of Novi Sad, Faculty of Technical Sciences, Trg Dositeja Obradovica 6, Novi Sad, Serbia \\ ${ }^{* * *}$ State University of Novi Pazar, Vuka Karadzica bb, Novi Pazar, Serbia \\ E-Mail: vukelic@uns.ac.rs
}

\begin{abstract}
Wrong or inadequate design and manufacture of modular fixtures can lead to deformations and displacements of workpiece and fixture-workpiece assembly, as well. Deformations and displacements can significantly impact final workpiece accuracy, rendering the fixture less efficient. With that in mind, this paper reviews development of a novel multi-purpose solution for a modular fixture design with higher efficiency, higher accessibility and flexibility. The results of simulations and modelling indicate that the proposed modular fixture design has advantages over the existing, conventional modular fixtures. The proposed framed structure of modular fixtures exhibits versatility in that it allows reliable locating and clamping of workpieces featuring complex geometry and shape. The novel design solution for modular fixtures opens new directions for future investigation, regarding selection and optimization of materials, shape and geometry of fixture elements which can be used to extend and upgrade modular fixtures. All this contributes to higher workpiece quality and accuracy, as well as the higher productivity and lower production costs.

(Received in June 2017, accepted in November 2017. This paper was with the authors 2 months for 1 revision.)
\end{abstract}

Key Words: Modular Fixture, Fixture Layout, Fixture Modelling, Fixture Simulation

\section{INTRODUCTION}

Modular fixtures are based on the modular principle, meaning that they use a set of a larger number of standard, typified elements (modules) which allow fast and accurate fixture assembly. Fixture elements are made in a number of different types, each type available in several dimensions. Considering the fact that modular fixture sets consist of a larger number of typified elements of constant shape, dimensions, and tolerances, with the geometric information on each of the constituent set elements being known in advance, modular fixtures have been focused by some previous investigations [1,2].

Modular fixtures, i.e., their design, construction and exploitation, also suffer from some disadvantages. The sets are expensive due to necessity for high quality and accuracy of elements, accompanied by high-priced steel. Limited number of sets can reduce flexibility of modular fixture, especially in the case of locating and clamping of complex-geometry, miniature, or massive workpieces. Larger number of sets allows reduced number of possible locating and clamping schemes. However, accuracy is also diminished considering that each element (module) contributes to assembly error (module manufacture error, and module assembly error). In addition, existence of a larger number of contact interfaces between modules, affects the fixture assembly stiffness $[3,4]$.

Extensive investigations have been conducted in the area of design and optimization of modular fixtures, which pertain to location efficiency, tolerance and stability analysis, analysis of possible limitations, and clamping force optimization. Besides the mentioned topics, previous investigations also comprise methods for determination of analytical and empirical models for defining locating and clamping schemes, kinetic analysis based on planning of locating and clamping, analysis of accessibility of particular cutting tools, as well 
as the analysis of fixture geometry. Large number of studies dealt with the FEM analysis of stresses, deformations and displacements within the workpiece/fixture system. Also, various methods of artificial intelligence were employed to optimize design of modular fixtures.

For example, Liqing and Senthil Kumar [5] developed an internet-enabled case-based reasoning (CBR) system for modular fixture design. This CBR system was focused on representing XML-based fixture design cases using unified modelling language. Mervyn et al. [6] proposed an evolutionary search algorithm for design of modular fixture. The algorithm integrated the search for fixture layouts and fixture configurations, allowing solutions to be sought concurrently accounting for the constraints in the fixture layout and fixture configuration. Martin and Lombard [7] presented a conceptual fuzzy- based method, related to the generation of locating points for the positioning modular fixture element. Violante et al. [8] showed a procedure based on reverse engineering (RE) and rapid prototyping techniques for the design and manufacturing of locating modular fixture elements that fit to the geometry of free-form component and provide stability and immobility. The main feature of these modular elements was that they were customized for the component itself, and fit to its real geometry captured by means of RE techniques. Bansal et al. [9] minimized the deviation in the machining zone due to the variation in size and thereby selected the position of locating and supporting modular fixture elements. Using three-dimensional tolerance analyses, they demonstrated that the modular fixture plans can be improved by changing the locating plane height. Wu et al. [10] described an analytical approach to modular fixture planning. The methodology defined the alternative of location plans by using linkage mechanism theory, performed accessibility and fixturability analysis and generated feasible clamping positions. Ameri and Summers [11] introduced an ontology for conceptualization and representation of domain knowledge in fixture design process. The proposed ontology was based on description logic, knowledge representation formalism and their interrelations. Zheng et al. [12] proposed an FE model to predict fixture unit stiffness by introducing nonlinear contact elements on the contact surface between fixture components. Nonlinearity was defined using the penalty function method and was solved by the modified Newton-Raphson procedure. Ryll et al. [13] presented methodologies for reconfiguration and part-to-fixture positioning. The modular fixturing system consisted of movable actuators and sensors. The part-to-fixture positioning approach was based on dimensional tolerances. The reconfiguration methodology was based on an object-oriented approach. Zheng and Qian [14] elaborated a mathematical model and a prototype of a new modular fixture. Efficient algorithms ware presented for computing optimal fixed locations for the given object pose regarding localization accuracy and immobilization capability. Vukelic et al. [15] presented an integral system for modular fixture selection, modification, and design. Knowledge-based methodology and case-based reasoning methodology were combined to develop a complex system for computer-aided modular fixture design. Peng et al. [16, 17] developed a virtual reality system for modular fixture configuration design and assembly. The proposed algorithm used the hybrid approach of space decomposition and bounding volume method. Hunter Alarcon et al. [18] developed a knowledge-based method for modular fixture design. The integrated definition for function modelling technique was used to define the fixture design process and to identify units of knowledge. Chaari et al. [19] established a method based on homogeneous transformation method in subject to determine the kinematic deviations caused by workpiece locating/relocating. Dynamic displacements due to clamping and machining forces were defined using FE method. Vishnupriyan et al. [20] presented a novel approach for the prediction of workpiece dynamic motion using an artificial neural network (ANN). Using a modular fixture set-up, different layouts were obtained. Parameters of the ANN were optimized using a genetic algorithm. Vukelic et al. [21] presented a new clamping method based on specially designed clamping element with a round cutting tool insert mounted on its 
tip. The specially designed clamping element increased workpiece-fixture load capacity and diminished interface compliance. Zeng et al. [22] developed a dynamic model of workpiecefixture-cutter system. They were focused on suppressing the machining vibration of the workpiece by selecting appropriate fixture layout. Tadic et al. [23] proposed a fixturing model for complex-geometry workpiece under multiple constraints. Locating of complex-geometry workpieces with two skewed holes was efficiently performed using mandrels which were positioned and fixed in workpiece holes. Wan and Zhang [24] presented a novel nonlinear programming problem based on the frequency sensitivity to optimize fixture layout supports to maximize the fundamental nature frequency of the workpiece-fixture system. Wan et al. [25] presented a self-selection reasoning method based on a smart modular fixture unit which can push unit selection scope and drive its size actively. The authors put forward the concept of smart fixture unit, and defined its ontology model. Tadic et al. [26] presented a method which uses only one surface for fixturing. This method provided stability for small workpieces, with locating and clamping over the bottom side which is necessary for machining in five planes. Munoa et al. [27] introduced a damping module for modular fixturing systems based on the concept of variable-stiffness tuned mass damper (VSTMD). This VSTMD allowed optimum performance along a wide frequency range and was adaptable to different modular fixtures. Vukelic et al. [28] described an intelligent system for modular fixtures optimization and design. The system was based on geometry and feature workpiece characteristics, machining and process planning information. Kongchuenjai and Prombanpong [29] proposed an integer programming approach for modular fixture planning. This research determined an optimal solution modular fixture for a workpiece manufactured on a machining centre. Ivanov et al. [30] based their investigation on numerical simulation and harmonic analysis and proposed the new configuration of modular fixture for ensuring the sufficient tool accessibility and lubricant effect (described additionally by Tic et al. [31]), which allows carrying out multiaxis machining of levers.

Considering present machining conditions, characterized by high cutting speeds, high feeds and chip cross-sections, accompanied by relatively high cutting forces, special attention should be placed on design and optimization of modular fixtures and their elements, to allow higher accessibility, flexibility and stiffness. Instead of merely detecting unfavourable responses in the workpiece/fixture system, investigations should be primarily focused on the methods which allow the design of more reliable modular fixtures.

In contrast to previous investigations, the goal of this study is to develop a novel design solution for modular fixtures, with higher accessibility and flexibility, without compromising the existing stiffness. The basic idea behind the concept of higher accessibility is to provide as much surface area for the access of cutting tools during machining, as possible. The increase of flexibility pertains to increased number of locating and clamping schemes, i.e., larger number of locating and clamping points. With that in mind, it is necessary to design modular fixtures which will allow higher efficiency compared to conventional modular fixtures which are in widespread use today. This should be accompanied by the minimal costs of modular fixture production.

\section{THEORETICAL BACKGROUND}

Every displacement at the contact interface between the elements of a modular fixture impacts the total displacement in the machining process. For that reason, it is of vital importance to minimize largest displacements, i.e., displacements which occur at the critical contact interface spots.

All element interfaces have compliance (displacement caused by force $F$ ), where the magnitude of displacement depends on a number of factors related to external loads and 
mechanical/physical characteristics of the constituent elements. Workpiece displacement primarily depends on the displacement of: machine tool work table $\left(\xi_{w t}\right)$, fixture body $\left(\xi_{f b}\right)$, locating elements $\left(\xi_{l e}\right)$ and clamping elements $\left(\xi_{c e}\right)$. If the workpiece displacement is considered in just one axis direction ( $x$ axis), the displacement vector $\left(\xi_{w p}\right)$ represents sum of all displacement vectors in the direction of that axis (Fig. 1). Locating and clamping elements are in direct contact with workpiece, thus exerting the greatest impact on the machining stability.

In dynamic machining conditions, the cutting force, which acts upon the workpiece, changes magnitude and direction. The forces which tend to displace the workpiece, do not just act in one direction as shown in Fig. 1 a, but are arranged in various planes, and defined by vectors of various orientations. It is the sum of all such forces acting upon the workpiece that shall cause the total displacement. Workpiece displacement vector shall be equal to the sum of all displacement vectors along $x, y$, and $z$ axes. Largest workpiece displacement which occurs during machining is the displacement of the modular fixture $\left(\xi_{m f}\right)$. Considering that the workpiece is in direct contact with the locating and clamping elements, they shall exert largest influence on the stiffness, i.e., displacement of workpiece, while the smallest contribution stems from the fixture body displacement $\left(\xi_{f b}\right)$ and work table displacement $\left(\xi_{w t}\right)$, respectively, as shown in Fig. 1 b. Displacement, which is the result of contact interface compliance between clamping and locating elements and workpiece, is directly related to machining errors.

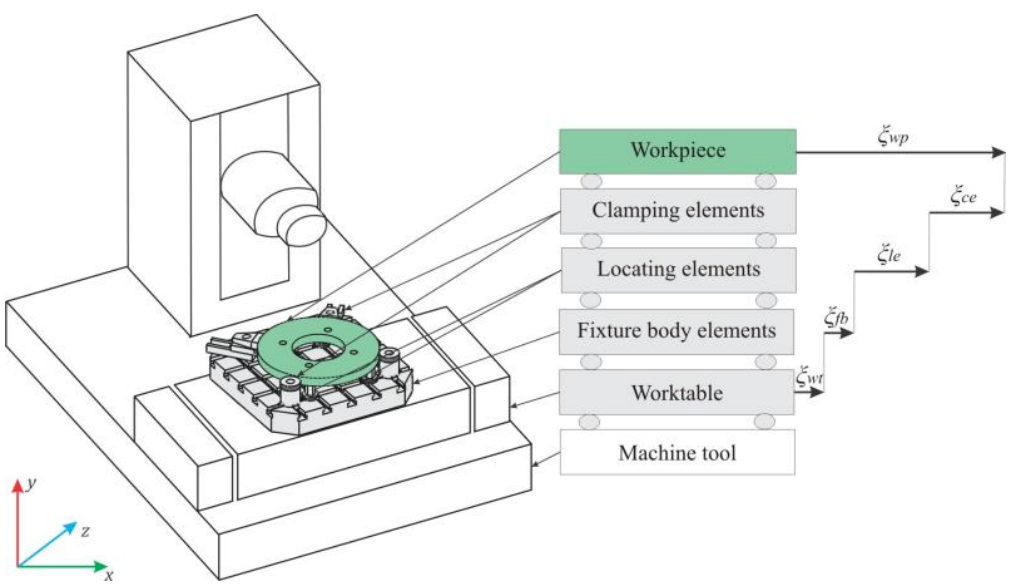

a) in the direction of $x$ axis

Figure 1: Workpiece displacements.

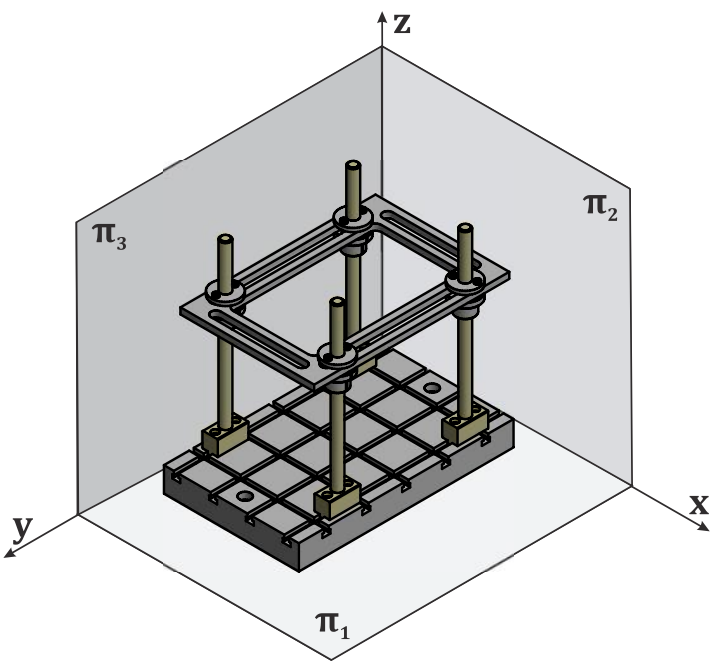

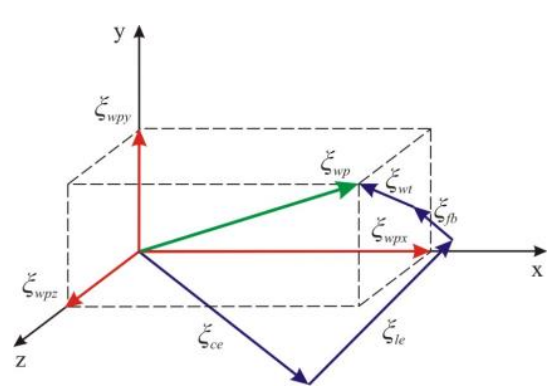

b) in space

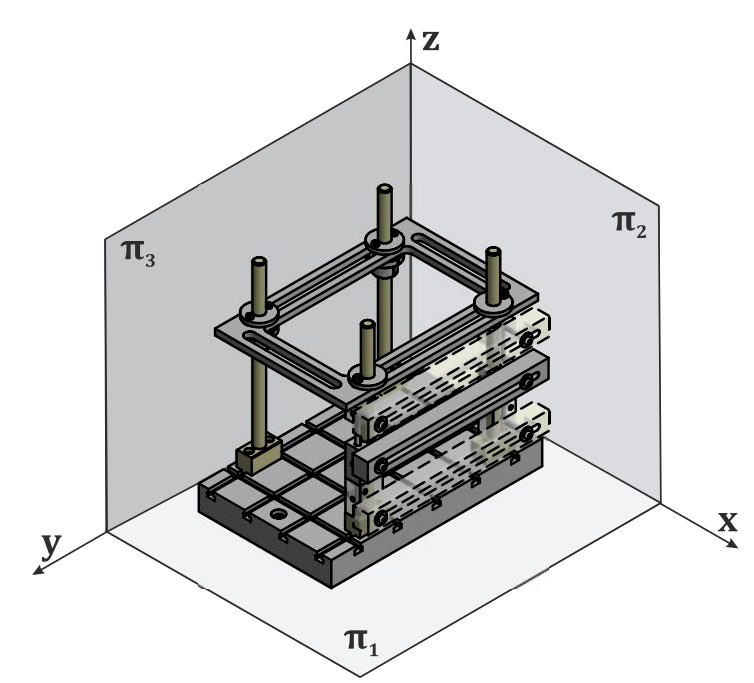

Figure 2: Assumptions for accessibility and flexibility of modular fixtures. 
The basic idea behind accessibility of modular fixtures rests upon providing the greatest possible amount of surface area available for cutting tools to access workpiece during machining, while the flexibility pertains to providing the largest possible number of locating and clamping points for various workpiece geometric shapes and sizes. When considering the problems of accessibility and flexibility of mounting frame modular fixtures, one should focus on the assumption that such fixture should have as much unobstructed surface area as possible. Whenever a new fixture element is added, the free surface area for the placement of locating and clamping elements is reduced, while also impeding free access to the cutting tools (Fig. 2).

With that in mind, basic configuration of the mounting frame- type modular fixture can be defined (Fig. 3). The mounting frame of such modular fixture is positioned at the sides of the base plate, which facilitates connection to other modular fixture elements. The basic structure of the proposed type of modular fixture comprises base plate (1), pillars (2), mounting frame (3) and connection elements (4).

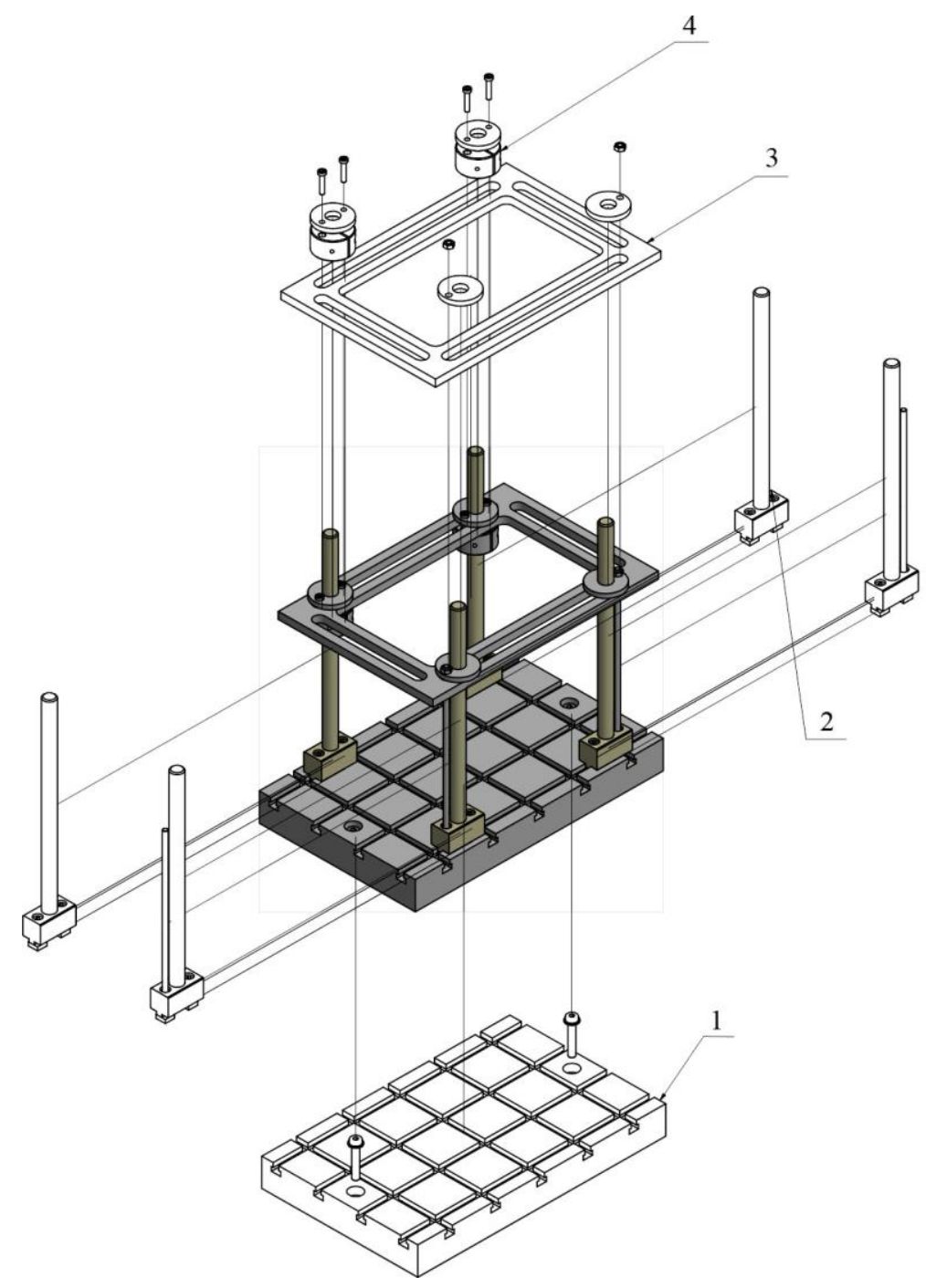

Figure 3: Basic configuration of the mounting frame modular fixture ( 1 - base plate, 2 - pillar, 3 - mounting frame element, 4 - connection element).

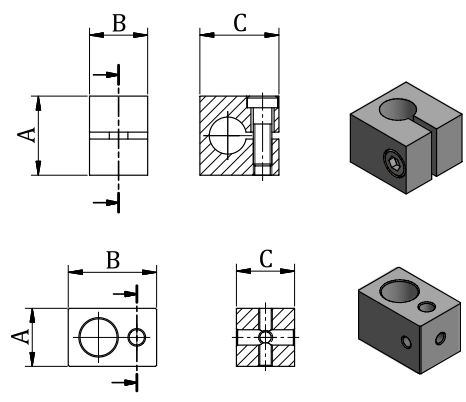

Figure 4: Stiffness enhancing elements.

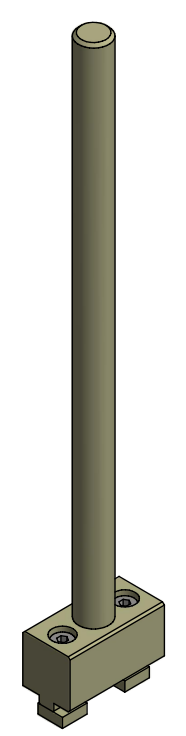

a) without stiffness enhancing element

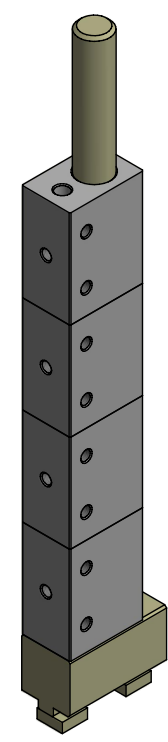

b) with stiffness enhancing elements
Figure 5: Pillar.

The base plate (1) is fundamental for modular fixtures. It has rectangular form with Tgrooves which feature narrow tolerances. The advantage of such base plate design lies in its adaptability and ease of locating of all other elements. In addition, the T-grooves provide 
much higher stiffness in comparison with the base plate which features openings. Once the pillars (2) are fixed to the base plate (1), the basic mounting frame modular fixture is set up. The pillars (2) can be machined to various dimensions. The role of the mounting frame element (3) is to form the support structure for the modular fixture. Therefore, the mounting frame (3) is set on the pillars (2) and fixed at the desired height from the base plate (1), using connection elements (4). The mounting frame element (3) also hosts workpiece clamping elements. The clamping elements can be fixed in any desired position along the grooves on the mounting frame element (3). Pillars (2) are fixed to the mounting frame element (3) using connection elements (4). Screws are used to tighten the upper and lower sections of the connection element (4), thus providing immobility of the mounting frame element (3) at the desired height. The square shaped stiffness enhancing elements (Fig. 4) are mounted on the pillars (Fig. 5). Once the stiffness enhancing elements are mounted, the cross-section of the pillars is changed from circular to rectangular, which increases the load capacity of pillars and their stiffness. To suit practical requirements, the stiffness enhancing elements can be mounted on one or more pillars. Moreover, the stiffness enhancing elements can be mounted anywhere along the entire pillar length, thus providing it with a constant cross-section area and a constant moment of inertia.

All of the discussed fixture elements are mounted onto the base plate, which is then fixed and screwed into the machine tool work table. Selection of modular elements depends on several factors: workpiece shape, geometry and dimensions; location of workpiece inside modular fixture; surfaces available for locating and clamping; the type, shape, geometry and dimensions of fixture elements; the clamping and cutting forces (moments).

\section{RESULTS}

Assessment of accessibility, flexibility and stiffness of the proposed modular fixture design has been compared to the existing design solutions for modular fixtures. With this in mind, a mounting frame modular fixture has been designed to accommodate workpieces of extremely complex geometries and large overall dimensions, for which there already exist conventional modular fixture solutions. More precisely, a total of six design solutions for modular fixtures were realized and compared. For three characteristic workpiece types - gearbox housing, transmission housing, and multiplicator housing - two modular fixture design solutions were fabricated to accommodate cast and forged workpieces (Fig. 6).

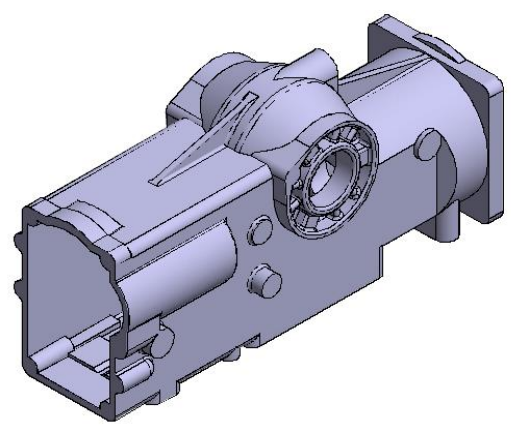

gearbox housing

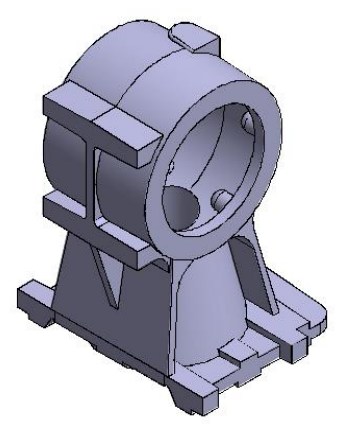

multiplicator housing

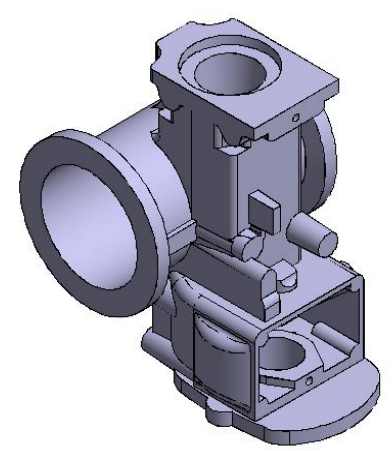

transmission housing

Figure 6: Workpieces.

Based on the already existing design solutions for conventional modular fixtures (Fig. 7), which were designed and assembled to accommodate a group of similar workpieces, mounting frame modular fixtures were designed (Fig. 8) to verify superior accessibility, flexibility, and stiffness. 


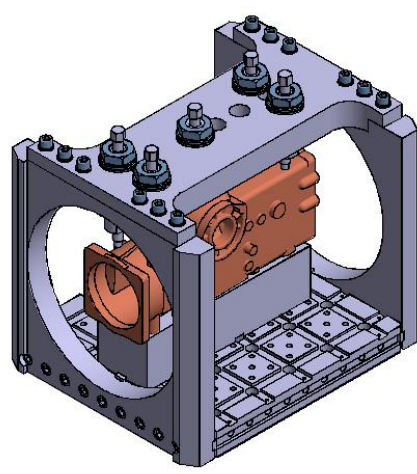

workpiece type: gearbox housing

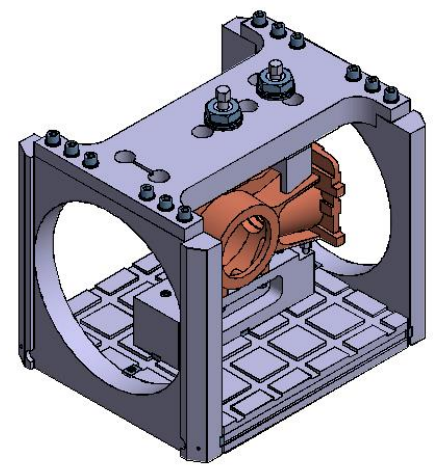

workpiece type: multiplicator housing

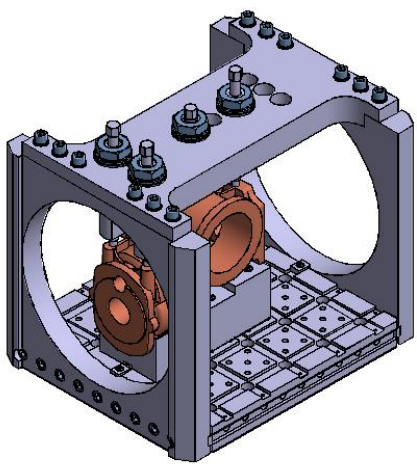

workpiece type: transmission housing

Figure 7: Conventional modular fixtures.

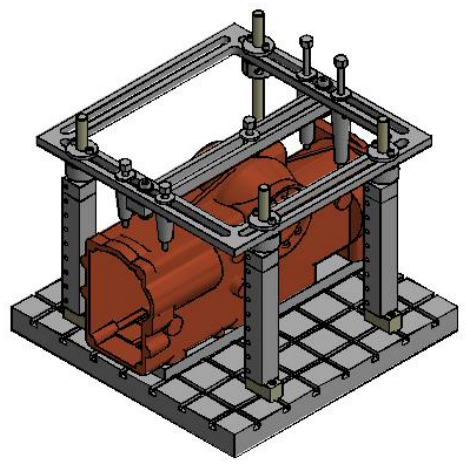

workpiece type: gearbox housing

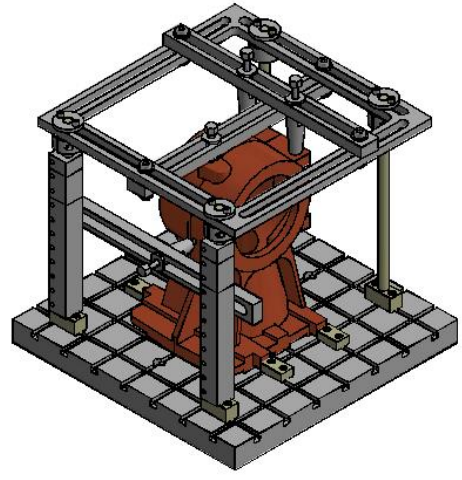

workpiece type: multiplicator housing

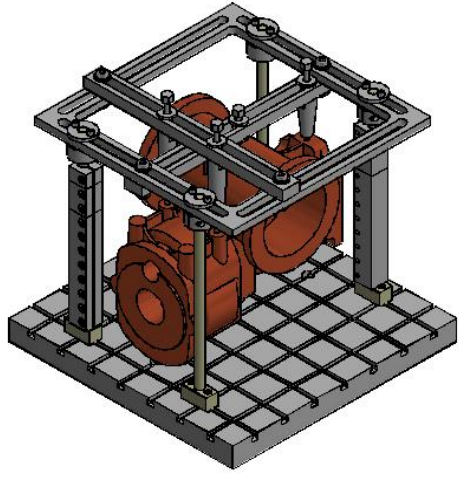

workpiece type: transmission housing

Figure 8: Mounting frame-type modular fixture.

\subsection{Assessment of accessibility and flexibility}

Accessibility and flexibility of modular fixtures can be assessed by three different parameters, namely: percent of free surface area for cutting tools access, number of available clamping points, and number of available workpiece locating points.

To calculate free surface area for tool access, and assess numbers of points for clamping and locating, for both fixture groups, CAD model (Figs. 7 and 8) was used. In order to determine the percent of free surface area $\left(A_{s}\right)$ within modular fixtures, total surface area $\left(A_{u}\right)$, and useful surface area $\left(A_{k}\right)$ were calculated. Total surface area included overall fixture dimensions, while the surface area of fixture elements was considered as useful surface area. Shown in Table I are results of assessment of designated surface areas on modular fixtures for the three workpiece types.

Percentage of free surface area $\left(A_{s}\right)$ is $22 \%$ greater in mounting frame modular fixtures than in their conventional counterparts. Also notable is the reduction of total surface area of mounting frame modular fixtures $\left(A_{u}\right)$, which represents improvement considering machine tool workspace.

Workpiece locating and clamping in both groups of modular fixtures was realized over identical surfaces. Conventional modular fixtures allowed clamping in eight points, while workpiece location was possible in just one way. In the case of mounting frame modular fixtures, the number of locating points is several times greater, while locating can be performed in several ways, for all three design solutions. 
Matejic, Tadic, Lazarevic, Misic, Vukelic: Modelling and Simulation of a Novel Modular ...

Table I: Characteristic surfaces areas.

\begin{tabular}{|l|c|c|c|c|c|c|}
\hline \multirow{2}{*}{ Workpiece } & \multicolumn{3}{|c|}{ Conventional modular fixture } & \multicolumn{3}{c|}{ Mounting frame-type modular fixture } \\
\cline { 2 - 7 } & $\boldsymbol{A}_{\boldsymbol{u}}\left(\mathrm{mm}^{2}\right)$ & $\boldsymbol{A}_{\boldsymbol{k}}\left(\mathrm{mm}^{2}\right)$ & $\boldsymbol{A}_{\boldsymbol{s}}(\%)$ & $\boldsymbol{A}_{\boldsymbol{u}}\left(\mathrm{mm}^{2}\right)$ & $\boldsymbol{A}_{\boldsymbol{k}}\left(\mathrm{mm}^{2}\right)$ & $\boldsymbol{A}_{\mathbf{s}}(\%)$ \\
\hline Gearbox housing & $150,800,000$ & $112,560,000$ & 75 & $68,850,000$ & $66,840,472$ & 97 \\
\hline Multiplicator housing & $150,800,000$ & $112,560,000$ & 75 & $68,850,000$ & $66,840,472$ & 97 \\
\hline Transmission housing & $150,800,000$ & $112,560,000$ & 75 & $68,850,000$ & $66,840,472$ & 97 \\
\hline
\end{tabular}

\subsection{Stiffness assessment}

FEM analysis was used to compare the stiffness of mounting frame modular fixtures to their conventional counterparts, for the workpieces shown in Fig. 6.

Conventional modular fixture

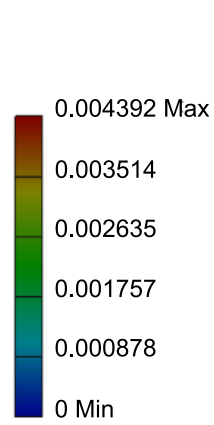

Mounting frame-type modular fixture

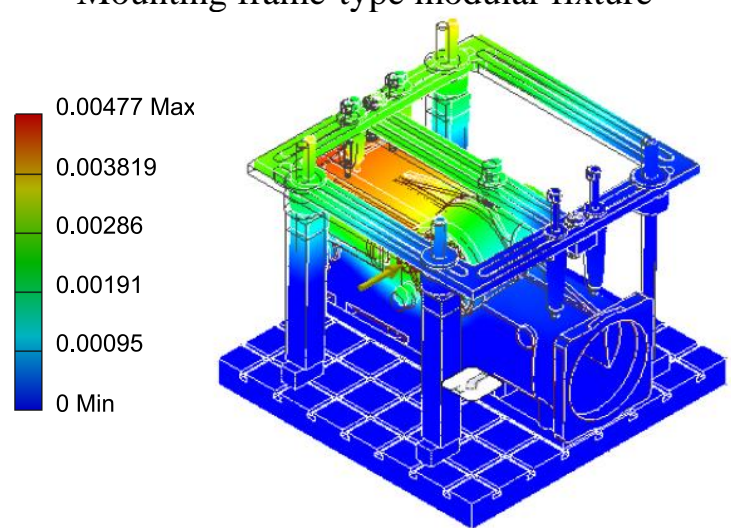

workpiece type: gearbox housing
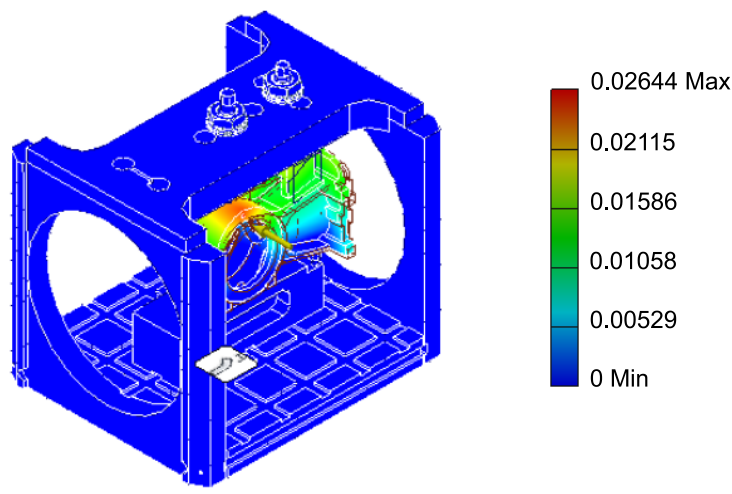

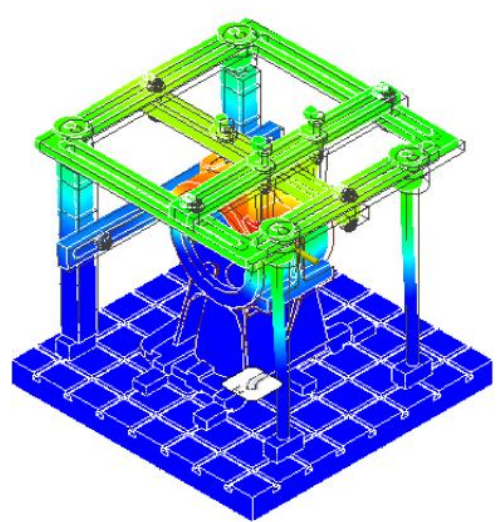

workpiece type: multiplicator housing
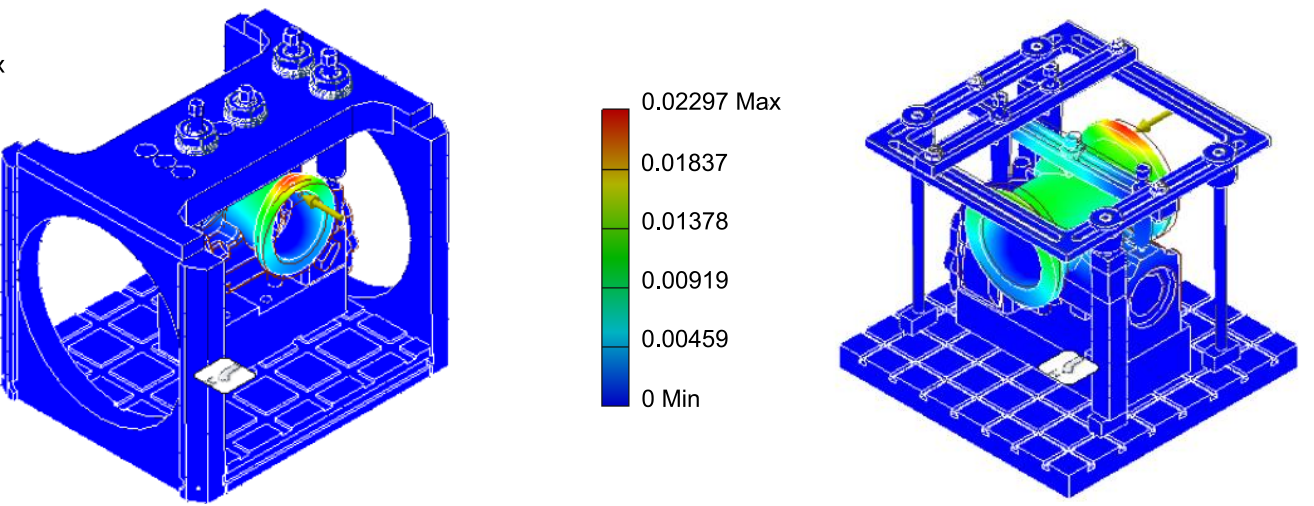

workpiece type: transmission housing

Figure 9: FEM analysis of workpiece/fixture assembly displacement for both types of modular fixtures, under the cutting force of $F=1000 \mathrm{~N}$. 
For the purpose of FEM analysis, maximum cutting force of $F=1000 \mathrm{~N}$ was input, with the correctly defined direction and sense. Following material parameters were adopted for workpiece material: Young modulus $E=70 \mathrm{GPa}$, Poisson ratio $m=0.33$, and density $q=2.70$ $\mathrm{g} / \mathrm{cm}^{3}$, while the material used for fixture elements was defined by: Young modulus $E=193$ $\mathrm{GPa}$, Poisson ratio $m=0.3$, and density $q=7.92 \mathrm{~g} / \mathrm{cm}^{3}$. All contact interface zones between fixture elements and workpiece were also defined, while the boundary conditions constrained base plate displacement in all directions to zero. Finally, the model was meshed using tetrahedral finite elements with four nodes, which resulted in a total number of 126,304 nodes. The size of finite elements was $0.5 \mathrm{~mm}$, with a refinement of $0.01 \mathrm{~mm}$ in the contact interface zone. Shown in Fig. 9 are workpiece/fixture assembly displacements upon the application of cutting force, for the conventional and mounting frame modular fixtures.

Comparison between stiffness results (Table II) for both fixture types, one concludes that the conventional modular fixture design has a marginal advantage over its mounting frame counterpart. On the other hand, the mounting frame design solution used in this example, has only partially exploited advantages offered by the stiffness enhancing elements. The number of stiffness enhancing elements used with the proposed fixture solution for the multiplicator and transmission housings was only $50 \%$ of the total possible number. Furthermore, the design solution for the modular fixture for gearbox housing clearly indicates the efficiency of the proposed mounting frame methodology. More specifically, in that example, stiffness enhancing elements were applied on three pillars. Even in such unfavourable case, the resulting stiffness was just $9 \%$ below that of the conventional modular fixture.

Table II: Comparative analysis of maximal displacements $\xi_{\max }$ and stiffness $k$ for the modular fixtures.

\begin{tabular}{|l|c|c|c|c|}
\hline \multirow{2}{*}{ Workpiece } & \multicolumn{2}{|c|}{ Conventional modular fixture } & \multicolumn{2}{c|}{ Mounting frame-type modular fixture } \\
\cline { 2 - 5 } & $\boldsymbol{\xi}_{\max }(\mathrm{mm})$ & $\boldsymbol{k}(\mathrm{N} / \mathrm{mm})$ & $\boldsymbol{\xi}_{\max }(\mathrm{mm})$ & $\boldsymbol{k}(\mathrm{N} / \mathrm{mm})$ \\
\hline gearbox housing & 0.00439 & $227,686.70$ & 0.00477 & $209,643.61$ \\
\hline multiplicator housing & 0.01003 & $99,700.90$ & 0.02644 & $37,821.48$ \\
\hline transmission housing & 0.01785 & $56,022.41$ & 0.02297 & $43,535.05$ \\
\hline
\end{tabular}

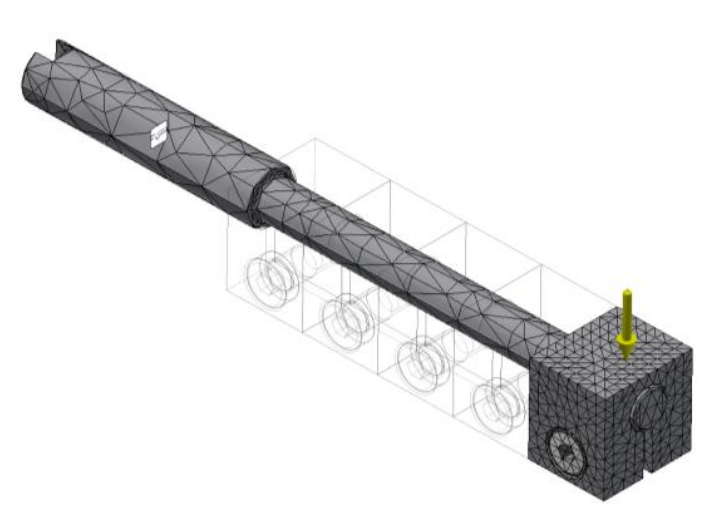

Figure 10: FEM analysis of displacements at the mounting frame pillar.

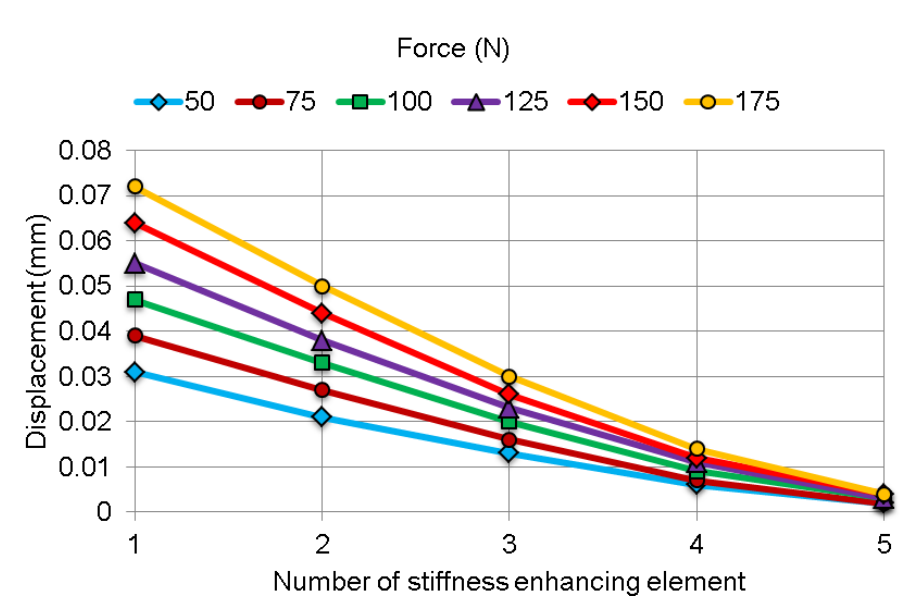

Figure 11: Pillar displacements, depending on the number of applied stiffness enhancing elements, for various force magnitudes.

One of the ways to enhance stiffness of the proposed mounting frame modular fixtures is to increase the diameter of pillars, which, on the other hand, incurs additional costs.

Also, additional stiffness enhancing elements added to the remaining pillars, would allow mounting frame solution to completely nullify the difference in stiffness for the two types of fixtures. 
Numerical simulation of displacements (deflections) at one end of the pillar, as the function of load magnitude, for the given number of enhancing elements applied to the pillar, is shown in Fig. 10.

Shown in Fig. 11 are numerically simulated displacements at one end of the pillar, as the function of load magnitude, for the given number of enhancing elements applied to the pillar. As seen from the figure, it is obvious that the displacement diminishes with the increased number of stiffness enhancing elements. For lower force magnitudes, and a smaller number of stiffness enhancing elements, displacements vary, ranging from $0.031 \mathrm{~mm}$ to 0.072 . With the increased number of stiffness enhancing elements, the displacements exhibit a significant drop and are practically equalized $(0.002-0.004 \mathrm{~mm})$, regardless of the load magnitude. This phenomenon supports the claim that stiffness enhancing elements can significantly reduce the displacement, i.e., increase the stiffness. By adding additional stiffness enhancing elements, i.e., increasing pillar cross-sectional area by transforming the circular profile to rectangular, the deflection is decreased by several times.

\section{CONCLUSION}

Investigations of modular fixtures have so far been focused mainly on the development of systems for their automated design, which was based on the existing sets of fixture elements (systems with openings and/or grooves). The approach used in this study is original in that it proposes a novel type of mounting frame modular fixtures with the primary aim to enhance accessibility, flexibility, and stiffness of modular fixtures.

Positive effects of the proposed approach to assembling modular fixtures reflect in the increased fixture reliability, machining accuracy, and productivity, due to sharper cutting regimes.

Based on the analysis of results, it can be concluded that the proposed mounting frame design solution has significant advantages compared to the conventional modular fixture solutions, which is primarily reflected in the much larger useful surface area which allows access to cutting tools. This is extremely important, considering modern manufacturing conditions, where it is of primary importance to allow machining of a number of workpiece surfaces with multiple cutting tools, in just one location and setup. In this way, machining accuracy (dimensional and geometric) is significantly enhanced, together with quality and productivity.

In addition, the results show increased flexibility of mounting frame modular fixtures. This is evident from the increased number of potential points for workpiece locating and clamping.

In the case of gearbox housing fixture, the results of numerical simulations indicate that the proposed mounting frame modular fixture lagged only $9 \%$ behind its conventional counterpart, with just $50 \%$ of the stiffness enhancing elements used. Moreover, the application of mounting frame design allowed several times more locating and clamping points, contributing to $22 \%$ increase in fixture accessibility.

Comparative analysis of numerical simulations obtained for both types of modular fixtures, it can be concluded that the conventional design solutions have slight advantage over the proposed mounting frame counterpart. With just small additional interventions, the mounting frame modular fixtures can meet the required stiffness demands. That can be achieved by increasing the number of stiffness enhancing elements, enlarging the crosssectional area of pillars, and/or by changing the cross-section geometry of pillars from circular to rectangular. 
The study presented in this paper can have a significant practical industrial application, considering the current trends towards machining with multiple cutting tools in one location and setup, in various cutting planes.

\section{REFERENCES}

[1] Girish, T.; Ong, S. K.; Nee, A. Y. C. (2003). Managing modular fixture elements with Tabu search in a Web-based environment, International Journal of Production Research, Vol. 41, No. 8, 1665-1687, doi:10.1080/1352816031000075008

[2] Boyle, I.; Rong, Y.; Brown, D. C. (2011). A review and analysis of current computer-aided fixture design approaches, Robotics and Computer-Integrated Manufacturing, Vol. 27, No. 1, 112, doi:10.1016/j.rcim.2010.05.008

[3] Bakker, O. J.; Papastathis, T. N.; Popov, A. A.; Ratchev, S. M. (2013). Active fixturing: literature review and future research directions, International Journal of Production Research, Vol. 51, No. 11, 3171-3190, doi:10.1080/00207543.2012.695893

[4] Gothwal, S.; Raj, T. (2017). Different aspects in design and development of flexible fixtures: Review and future directions, International Journal of Services and Operations Management, Vol. 26, No. 3, 386-410, doi:10.1504/ijsom.2017.10002780

[5] Liqing, F.; Senthil Kumar, A. (2005). XML-based representation in a CBR System for fixture design, Computer-Aided Design and Applications, Vol. 2, No. 1-4, 339-348, doi: $10.1080 / 16864360.2005 .10738382$

[6] Mervyn, F.; Senthil Kumar, A.; Nee, A. Y. C. (2005). Automated synthesis of modular fixture designs using an evolutionary search algorithm, International Journal of Production Research, Vol. 43, No. 23, 5047-5070, doi:10.1080/00207540500160904

[7] Martin, P.; Lombard, M. (2006). Modelling knowledge related to the allocation of modular jigs for part fixturing using fuzzy reasoning, International Journal of Advanced Manufacturing Technology, Vol. 28, No. 5-6, 527-531, doi:10.1007/s00170-004-2394-y

[8] Violante, M. G.; Iuliano, L.; Minetola, P. (2007). Design and production of fixtures for free-form components using selective laser sintering, Rapid Prototyping Journal, Vol. 13, No. 1, 30-37, doi: $10.1108 / 13552540710719190$

[9] Bansal, S.; Malik, P.; Reddy, N. V.; Saxena, A. (2008). Modular fixture planning for minimum three-dimensional tolerances using a neutral part data exchange format, International Journal of Production Research, Vol. 46, No. 6, 1455-1476, doi:10.1080/00207540600607267

[10] Wu, Y.; Gao, S.; Chen, Z. (2008). Automated modular fixture planning based on linkage mechanism theory, Robotics and Computer-Integrated Manufacturing, Vol. 24, No. 1, 38-49, doi: $10.1016 /$ j.rcim.2006.06.003

[11] Ameri, F.; Summers, J. D. (2008). An ontology for representation of fixture design knowledge, Computer-Aided Design and Applications, Vol. 5, No. 5, 601-611, doi:10.3722/cadaps.2008.601$\underline{611}$

[12] Zheng, Y.; Rong, Y.; Hou, Z. (2008). The study of fixture stiffness part I: a finite element analysis for stiffness of fixture units, International Journal of Advanced Manufacturing Technology, Vol. 36, No. 9-10, 865-876, doi:10.1007/s00170-006-0908-5

[13] Ryll, M.; Papastathis, T. N.; Ratchev, S. (2008). Towards an intelligent fixturing system with rapid reconfiguration and part positioning, Journal of Materials Processing Technology, Vol. 201, No. 1-3, 198-203, doi:10.1016/j.jmatprotec.2007.11.133

[14] Zheng, Y.; Qian, W.-H. (2008). A 3-D modular fixture with enhanced localization accuracy and immobilization capability, International Journal of Machine Tools and Manufacture, Vol. 48, No. 6, 677-687, doi:10.1016/j.ijmachtools.2007.10.022

[15] Vukelic, D.; Zuperl, U.; Hodolic, J. (2009). Complex system for fixture selection, modification, and design, International Journal of Advanced Manufacturing Technology, Vol. 45, No. 7-8, 731-748, doi:10.1007/s00170-009-2014-y

[16] Peng, G.; Wang, G.; Liu, W.; Yu, H. (2010). A desktop virtual reality-based interactive modular fixture configuration design system, Computer-Aided Design, Vol. 42, No. 5, 432-444, doi: $\underline{10.1016 / j . c a d .2009 .02 .003}$ 
[17] Peng, G.; Hou, X.; Wu, C.; Jin, T.; Zhang, X. (2010). Fast collision detection approach to facilitate interactive modular fixture assembly design in a virtual environment, International Journal of Advanced Manufacturing Technology, Vol. 46, No. 1-4, 315-328, doi:10.1007/s00170-009-2073-0

[18] Hunter Alarcon, R.; Rios Chueco, J.; Perez Garcia, J. M.; Vizan Idoipe, A. (2010). Fixture knowledge model development and implementation based on a functional design approach, Robotics and Computer-Integrated Manufacturing, Vol. 26, No. 1, 56-66, doi:10.1016/j.rcim.2009.02.001

[19] Chaari, R.; Abdennadher, M.; Louati, J.; Haddar, M. (2011). Modelling of the 3D machining geometric defects accounting for workpiece vibratory behaviour, International Journal of Simulation Modelling, Vol. 10, No. 2, 66-77, doi:10.2507/IJSIMM10(2)2.173

[20] Vishnupriyan, S.; Muruganandam, A.; Govindarajan, L. (2012). Prediction of workpiece dynamic motion using an optimized artificial neural network, Proceedings of the Institution of Mechanical Engineers, Part B: Journal of Engineering Manufacture, Vol. 226, No. 10, 1705-1716, doi: $10.1177 / 0954405412457121$

[21] Vukelic, D.; Tadic, B.; Miljanic, D.; Budak, I.; Todorovic, P. M.; Randjelovic, S.; Jeremic, B. M. (2012). Novel workpiece clamping method for increased machining performance, Tehnicki vjesnik - Technical Gazette, Vol. 19, No. 4, 837-846

[22] Zeng, S.; Wan, X.; Li, W.; Yin, Z.; Xiong, Y. (2012). A novel approach to fixture design on suppressing machining vibration of flexible workpiece, International Journal of Machine Tools and Manufacture, Vol. 58, 29-43, doi:10.1016/j.ijmachtools.2012.02.008

[23] Tadic, B.; Bogdanovic, B.; Jeremic, B. M.; Todorovic, P. M., Luzanin, O.; Budak, I.; Vukelic, D. (2013). Locating and clamping of complex geometry workpieces with skewed holes in multipleconstraint conditions, Assembly Automation, Vol. 33, No. 4, 386-400, doi:10.1108/aa-09-2012$\underline{074}$

[24] Wan, X.-J.; Zhang, Y. (2013). A novel approach to fixture layout optimization on maximizing dynamic machinability, International Journal of Machine Tools and Manufacture, Vol. 70, 3244, doi:10.1016/j.ijmachtools.2013.03.007

[25] Wan, N.; Wang, Z.; Mo, R. (2013). An intelligent fixture design method based on smart modular fixture unit, International Journal of Advanced Manufacturing Technology, Vol. 69, No. 9-12, 2629-2649, doi:10.1007/s00170-013-5134-3

[26] Tadic, B.; Todorovic, P.; Novkinic, B.; Buchmeister, B.; Radenkovic, M.; Budak, I.; Vukelic, D. (2015). Fixture layout design based on a single-surface clamping with local deformation, International Journal of Simulation Modelling, Vol. 14, No. 3, 379-391, doi:10.2507/IJSIMM14(3)1.280

[27] Munoa, J.; Iglesias, A.; Olarra, A.; Dombovari, Z.; Zatarain, M.; Stepan, G. (2016). Design of self-tuneable mass damper for modular fixturing systems, CIRP Annals, Vol. 65, No. 1, 389-392, doi:10.1016/j.cirp.2016.04.112

[28] Vukelic, D.; Simunovic, G.; Tadic, B.; Buchmeister, B.; Saric, T.; Simeunovic, N. (2016). Intelligent design and optimization of machining fixtures, Tehnicki vjesnik - Technical Gazette, Vol. 23, No. 5, 1325-1334, doi:10.17559/tv-20150908142130

[29] Kongchuenjai, J.; Prombanpong, S. (2017). An integer programming approach for process planning for mixed-model parts manufacturing on a CNC machining center, Advances in Production Engineering \& Management, Vol. 12, No. 3, 274-284, doi:10.14743/apem2017.3.258

[30] Ivanov, V.; Mital, D.; Karpus, V.; Dehtiarov, I.; Zajac, J.; Pavlenko, I.; Hatala, M. (2017). Numerical simulation of the system "fixture-workpiece" for lever machining, International Journal of Advanced Manufacturing Technology, Vol. 91, No. 1-4, 79-90, doi:10.1007/s00170016-9701-2

[31] Tic, V.; Tasner, T.; Lovrec, D. (2014). Enhanced lubricant management to reduce costs and minimise environmental impact, Energy, Vol. 77, 108-116, doi:10.1016/j.energy.2014.05.030 